\title{
A IMAXE DAS SOLDADEIRAS NA LÍRICA MEDIEVAL GALEGO-PORTUGUESA
}

\section{THE IMAGE OF THE SOLDADEIRAS IN GALICIAN-PORTUGUESE LYRIC}

\author{
Lucía Sande Siaba ${ }^{1}$ \\ Universidade do Estado do Rio de Janeiro
}

Resumo: Este traballo céntrase na representación das soldadeiras nas cantigas de escarnio e maldizer da lírica medieval galego-portuguesa e ten como obxectivo reunir todas as características tanto físicas como psicolóxicas que son atribuídas a elas nas 43 cantigas nas que, segundo Graça Videira Lopes, aparecen mencionadas estas mulleres. Para isto, utilizarase o corpus de textos dispoñíbel na Base de datos da Lírica Profana Galego-Portuguesa do Centro Ramón Piñeiro para a Investigación en Humanidades, así como as antoloxías de Graça Videira Lopes e de Xosé Bieito Arias Freixedo, ademais doutros materiais aos que se irá facendo referencia ao longo do traballo. Con isto, preténdese ofrecer unha imaxe panorámica da representación das soldadeiras nas cantigas satíricas.

Palabras-chave: Lírica Galego-portuguesa; Sátira; Cantigas de escárnio e maldizer; Soldadeiras; Personaxe literaria; Mulleres Medievais; Tema literario.

1 lucia.s.siaba@gmail.com 
Abstract: This work focuses on the representation of the soldadeiras in the cantigas of derision of the Galician-Portuguese lyric, and has as its main objective to gather both all physical and psychological characteristics that are attributed to them in the 43 cantigas in which, according to Graça Videira Lopes, these women are mentioned. In order to achieve that, the corpus of texts available at the Centro Ramón Piñeiro para a Investigação em Humanidades's database of Galician-Portuguese lyric will be used along with Graça Videira Lopes's and Xosé Bieito Arias Freixedo's anthologies and other materials that will be referenced throughout this work. By doing that, there is the intention of offering a panoramic view of the representation of the soldadeiras in the satirical cantigas.

Keywords: Galician-Portuguese lyrics; Satire; Cantigas of derision; Soldadeiras; Literary character; Medieval women; Literary theme.

\section{INTRODUCIÓN}

Coa aparición dos estudos de xénero nas últimas décadas do século $X X$ foi crecendo o interese por entender o papel das mulleres no ámbito literario ao longo dos séculos e, hoxe en día, son moitas as investigacións publicadas sobre este tema desde diversas perspectivas. Unha das máis relevantes ten sido a da análise das representacións femininas en textos de autoría masculina tendo en conta a escaseza ou a inexistencia, como no caso da lírica medieval galegoportuguesa, de textos escritos por mulleres. Debido a esta falta de autoría feminina en determinadas épocas e contextos, moitos estudos veñen centrando o seu interese na participación das mulleres dentro do universo literario, non só como participantes do medio ou como creadoras, senón tamén como obxecto representado. No caso da literatura medieval galego-portuguesa son pioneiros neste ámbito os estudos de Mercedes Brea Dona e senhor nas cantigas de amor (1989) e, máis tarde, o de José Luis Rodríguez, que fixa a súa atención no xénero de escarnio no artigo $A$ mulher nos Cancioneiros. Notas para um anti-retrato descortês (1993) e a análise de Esther Corral que aborda as denominacións das donas na lírica profana e relixiosa no libro As mulleres nas cantigas medievais (1996), entre outros. A importancia da representación das mulleres nos textos de autoría masculina tórnase especialmente importante cando falamos da lírica medieval galego-portuguesa, xa que a pesar de non termos mulleres escritoras, 
a figura feminina constitúe o eixo fundamental no que se asentan os dous grandes xéneros amorosos: as cantigas de amor e as cantigas de amigo, nas que ademais, o suxeito lírico é feminino.

Se reparamos na imaxe que se transmite das mulleres nestes dous xéneros atoparémonos cunha serie de tópicos suxeitos a uns códigos léxicos e literarios bastante ríxidos herdados da tradición occitana, principalmente no caso das cantigas de amor. Nelas, a dama é representada como un ser superior e idealizado ao que se rende vasalaxe e ao que os trobadores se refiren como senhor, seguindo o tópico da utilización metafórica do código feudal. Ademais, a louvanza da dama faise dende un plano subxectivo para o que se utilizan formas moi vagas para referirse á fermosura do seu rostro, ao seu talle perfecto, á súa forma de ser (bon sen) ou á súa consideración social (bon prez), resaltando sempre a súa relación co divino e polo tanto incorpóreo (CORRAL, 2010, pp. 57-59).

No outro xénero amoroso, a cantiga de amigo, a pesar de que a muller que se describe continúa a ser ideal, aparecen certos elementos que se refiren á súa corporeidade a través da utilización dun vocabulario específico deste xénero como pode ser: velida, louçaa, delgada, corpo delgado, corpo velido, ben talhada... (CORRAL, 1996, p. 351). Atopamos aquí unha maior complexidade e variedade, pois introdúcense unha serie de motivos novidosos que atenden, sobre todo, á caracterización feminina. Ademais, insírense nesta tipoloxía novos personaxes femininos como a nai ou a amiga que actúan como confidentes ou conselleiras. A namorada é a que fai unha gabanza da propia fermosura a través do "autoeloxio" recorrendo a estilemas como fremosa, de bon parecer ou de mui bon prez. Como vemos, neste xénero tampouco aparecen descricións concretas debidas ao carácter abstracto da tradición galego-portuguesa, a pesar de atoparmos unha complexidade algo maior que na cantiga de amor no que se refire ao tratamento dos tipos femininos (CORRAL, 2010, pp. 71-73). 
No presente traballo analizarase a visión que a lírica medieval galegoportuguesa transmite dun grupo de mulleres moi concreto ao que se fai referencia unicamente nas cantigas de escarnio e maldizer: as soldadeiras. Mais para comprender a caracterización que se fai destas mulleres é preciso entender que a descrición das mulleres no xénero satírico se crea, na maior parte dos casos, por oposición á descrición das damas nos xéneros amorosos que acabamos de mencionar.

Coa finalidade de exemplificar cales son as características, tanto físicas como psicolóxicas, que máis recorrentemente se atribúen ás soldadeiras, analizaranse as 43 cantigas de 13 autores diferentes que, segundo Graça Videira Lopes, se dedican ás soldadeiras. Para isto utilizarase o corpus de textos dispoñíbel na Base de datos da Lírica Profana Galego-Portuguesa do Centro Ramón Piñeiro, así como as antoloxías de Graça Videira Lopes (2002) e de Xosé Bieito Arias Freixedo (1995), ademais doutros materiais aos que se irá facendo referencia ao longo do traballo.

\section{AS SOLDADEIRAS NA LÍRICA MEDIEVAL GALEGO- PORTUGUESA}

As soldadeiras eran mulleres que participaban no espectáculo trobadoresco cantando, bailando ou tocando instrumentos. Unha proba disto son algunhas das iluminuras do Cancioneiro da Ajuda, nas que aparecen unhas mulleres danzando acompañadas, en certos casos, de tarrañolas ou pandeiros, o que dá conta do importante papel que desenvolvían na execución da poesía lírica galego-portuguesa. Mais unha das cousas que máis sorprende destas mulleres é precisamente a elección do termo soldadeiras para referirse a elas nas cantigas de escarnio, xa que é o máis ambiguo dos que se podía escoller tendo en conta que existen outros termos como cantareiras ou xograresas. A denominación de soldadeira procede da palabra soldada ('cantidade de diñeiro 
coa que se pagaba aos soldados nas campañas militares') (CORRAL, 1996, p. 281), por tanto, esta palabra faría referencia ás mulleres que acompañaban aos soldados nas campañas militares e que recibían a soldada como pagamento polos seus servizos, en moitos casos de tipo sexual. $\mathrm{O}$ feito de que as mulleres que participaban do espectáculo trobadoresco recibisen o mesmo nome é unha proba da mentalidade misóxina da época que equiparaba, no discurso satírico, as mulleres artistas a simples prostitutas. Como di a investigadora Carmen Blanco (2005) sobre estas mulleres:

Nada se sabe certo das artes reais do corpo e da lírica daquelas mulleres da arte dos tempos pasados, soldadeiras, cantadeiras e xograresas que participaron activamente no florecemento da cultura trovadoresca medieval, no seu canto, na súa música, na súa danza, nos seus xogos e na súa vida alegre. Toda a real riqueza desta vida foise co vento da historia imposta e destas artistas hoxe certo non temos máis que o son dos seus nomes incertos [...] Nada quedou na historia do protagonismo artístico destas mulleres, tan só a creación fantasmagórica da mentalidade sexista, sexofóbica misóxina da corte alfonsí que instituíu o xénero da obscena sátira de soldadeira, apelando ao riso reprimido, represor e represivo, denigrador da muller de vida sexual libre e da prostituta que esa mesma mentalidade inventara para contrapor á outra creación fantasmagórica súa, a da Virxe, loada nas rexias Cantigas de Santa Maria (BLANCO, 2005, p. 18)

A oposición entre a prostituta e a santa á que fai referencia Carmen Blanco vai ser unha constante na historia da literatura, practicamente ata os nosos días. Esta dicotomía entre a "muller anxo" e a "muller demo" ou femme fatale gañou especial importancia na Idade Media a partir da difusión de dous estereotipos cristiáns opostos: o de Eva e á Virxe María. Na lírica profana galego-portuguesa veremos claramente esta oposición entre a imaxe das mulleres nos xéneros amorosos e nas cantigas de escarnio e maldizer. Analizando as características atribuídas ás soldadeiras veremos como as súas descricións son construídas por oposición á descrición que se realiza da dama nos xéneros amorosos. O vocabulario e os códigos literarios utilizados na 
maioría dos casos son os mesmos que na lírica amorosa, mais reflectindo trazos antitéticos.

\section{ADESCRICIÓN FÍSICA}

A descrición en termos físicos das soldadeiras, como da maioría das mulleres que aparecen nas cantigas satíricas, realízase habitualmente utilizando termos moi xerais. Un exemplo disto vémolo na cantiga de Alfonso X, Achei Sancha Anes encabalgada $(18,1)$, na que se di: "ca nunca vi dona peior talhada,/ e quige jurar que era mostea" (vv. 3, 4). Nótese que, ao chamar á soldadeira "mostea" ('carrada de palla'), estase aludindo tamén á súa gordura, que aparecería como un trazo negativo do seu aspecto físico. Neste caso obsérvase facilmente a oposición que se establece entre as mulleres nos xéneros amorosos e no escarnio, posto que se utiliza o mesmo léxico. Unha das formas máis comúns que se emprega para referirse a beleza física da muller nas cantigas de amigo é a forma bem talhada, que aquí vemos substituída por peior talhada sendo este un claro exemplo de contra-texto no que a crítica ao aspecto da dona se explícita de xeito directo.

Noutras ocasións as alusións á fealdade das mulleres exprésanse de xeito indirecto, como no caso de María Negra, á que Pero Garcia Burgalés $(125,9)$ se refire como bem talhada ("Dona Maria Negra, ben talhada,/dizen que sodes de mi namorada." (vv. 1, 2)) nun ton claramente irónico e non como no exemplo anterior, no que aparecía directamente, peior talhada. $\mathrm{O}$ autor sérvese, como no caso anterior, do léxico propio dos xéneros amorosos, pero en lugar de utilizalo co sentido contrario, aporta o matiz negativo a través da ironía. Ademais, nesta cantiga, dáselle a volta aos papeis propios do xénero amoroso, sinalando que neste caso é a muller a que está namorada do trobador. Trátase, pois, dun xogo de inversión de papeis. Pero da Ponte dedica a Marinha Foça a composición 
Marinha Foça quis saber $(120,22)$, na que se refire ao seu desagradábel aspecto físico tamén de xeito indirecto dicindo que nunca naceu quen a viu e a desexou: “-Senhor, non ouver'a nacer/quen vos viu e vos desejou!" (vv. 5, 6). Nesta cantiga, ao igual que nas anteriores, a utilización de léxico característico das cantigas de amor volve a estar presente, xa que o trobador se refire á soldadeira mediante a apóstrofe senhor. En canto á temática, a composición é bastante singular, posto que comeza coa vontade da soldadeira de saber cal é a opinión do trobador sobre o seu aspecto físico. Isto podería indicar certa vaidade pola súa parte ${ }^{2}$, ao considerar que o seu aspecto non era tan desagradábel. $\mathrm{O}$ autor responde nun ton claramente humorístico que non debía de nacer aquel que a vise e a desexase, resaltando un único risco físico, a súa negritude, á que fai referencia na terceira cobra,

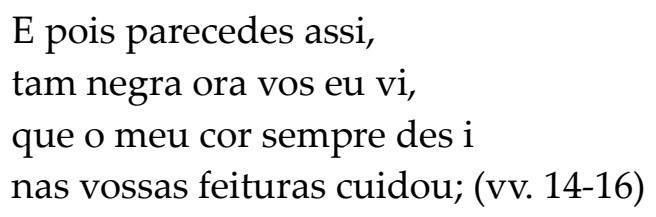

A cor negra é unha das características negativas que se asocian ás soldadeiras en oposición ao canon de beleza da época. Como sabemos, unha das únicas características físicas que se destaca da dama nos xéneros amorosos é a súa brancura de pel, polo que no escarnio atopamos en varias ocasións alusións á negritude de pel como trazo claramente negativo, sendo Negra un dos alcumes pexorativos que vemos aplicado a unha das soldadeiras nas composicións Dona Maria Negra, ben talhada (125,9), Maria Negra desventuyrada $(125,20)$ e Maria Negra vi eu, en outro dia $(125,21)$.

\footnotetext{
2 "Marinha Foça quis saber/ como lh'ia de parecer" (vv. 1, 2)
} 


\subsection{Os defectos físicos}

Os defectos físicos das soldadeiras son un dos temas máis comúns aos que recorren os trobadores para referirse a estas mulleres. É preciso ter en conta que participaban do espectáculo trobadoresco e que actuaban para o público, polo tanto, o seu aspecto físico debía ser importante, de aí que o humorismo se buscase en moitas ocasións a través da exposición dalgúns dos seus defectos. Este é o caso, por exemplo, de María Negra á que se refire Pero Garcia Burgalês no seu texto Maria Negra vi eu, en outro día $(125,21)$, no que o trobador inquire á soldadeira sobre a orixe do seu nome, ao que ela responde:

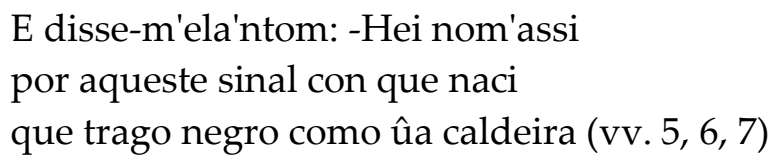

Na seguinte estrofa o trobador pregúntalle polo lugar onde tería ese sinal de nacemento ao que ela lle responde "arredor da caldeira" (v. 14), polo que, segundo Rodrigues Lapa, debía tratarse dunha mancha negra e cabeluda que tería en volta do sexo (LAPA, 1965, p. 567). Actualmente outros investigadores como o profesor Henrique Marques Samyn (2020) defenden que se tratase de unha persoa de raza negra e non de un sinal. Nesta cantiga vemos novamente a connotación negativa da cor negra aplicada ao corpo da muller estando presente neste caso, como xa comentamos no punto anterior, no alcume da soldadeira.

Unha composición especialmente rica, no que se refire ás mencións dos defectos físicos das soldadeiras, é Estavam oje duas soldadeiras $(64,11)$, de Joan Baveca, na que se reproduce o diálogo entre dúas soldadeiras. Nesta cantiga, cada unha das mulleres vai citando os principais defectos físicos da outra. Así a primeira que fala dille á outra "Que enrugadas olheiras teendes!" (v. 5), referíndose á vellez e cansazo que mostran os seus ollos, mentres que esta 
responde "Vós com'ar veedes/ desses cabelos sobr'essas trincheiras?" (v. 6-7), que segundo Rodrigues Lapa (1965, p. 295) se estaría referindo ao poboadas que son as súas cellas que mesmo lle impedirían ver. Nesta parte introdúcese outro elemento negativo que ata agora non aparecera como é o do exceso de pelo na face. Na terceira cobra unha delas menciona como son "covas essas caaveiras" (v. 21) para indicar que os seus ollos están moi afundidos o que indicaría novamente a vellez do seu rostro. Na última cobra utilízase o pretexto do baño para que ambas podan mencionar partes do seu corpo e non só da cara como fixeran ata ese momento. Así unha delas lle di á outra "mole ventr'havedes;/ e diss'a outr': -E vós mal o 'scondedes, as tetas que semelhan cevadeiras" (vv. 2628)

\subsection{A vellez}

Sen dúbida, a característica física na que máis se incide nas composicións dedicadas ás soldadeiras é a vellez, o que contrasta coa escaseza de referencias á idade da dama que atopamos nos xéneros amorosos. Xa que as soldadeiras eran mulleres que traballan de cara ao público, a beleza debía ser un dos seus instrumentos de traballo, polo que o seu deterioro físico debía estar ligado ao fin da súa actividade profesional. É por iso que en moitas ocasións a vellez das soldadeiras aparece asociada á pobreza. Non é de estrañar, por tanto, que en varias composicións as soldadeiras manifesten a súa preocupación polo feito de iren envellecendo.

O termo velha aparece en trece composicións de escarnio ${ }^{3}$ sendo sete delas dedicadas a soldadeiras: Orraca López vi doente un dia $(2,26)$, A $\hat{u} a$ velha quis ora trobar $(2,7)$ e Traj'agora Marinha Sabugal $(2,23)$ de Afonso Eanes do Coton; Achei Sancha Anes encabalgada $(18,1)$ de Alfonso X; Par Deus, amigos, gran torto

\footnotetext{
${ }^{3}$ Véxase para termos referidos á vellez E. Corral, As mulleres nas cantigas medievais (1996, p. 173180).
} 
tomei $(64,21)$ de Johan Baveca; Maria Negra, desventuyrada $(125,20)$ de P. Garcia Burgalês; Maria Leve, u se maenfestava $(81,10)$ de J. Vasquiz de Talaveira. Ademais, noutras moitas composicións ás referencias á vellez fanse de forma indirecta ao referirse ao paso do tempo a través dos defectos físicos das mulleres. Este é o caso, por exemplo, da cantiga de Johan Baveca comentada anteriormente, na que vimos como a maioría dos defectos físicos que as soldadeiras destacan unha da outra están asociados á vellez: as enrrugadas olheiras (v. 5); as sobrancelhas veiras, isto é, negras e brancas (v. 14); o mole ventre (v. 26) ou as tetas que semelhan cevadeiras (v. 28). Isto demostra que o peor risco do seu aspecto e o que máis as preocupaba era precisamente o rastro deixado polo paso dos anos nos seus corpos.

Na composición de Johan Vasquiz de Talaveira, na que aparece Maria Leve (Maria Leve, u se maenfestava, 81,10) atopamos un caso similar. A soldadeira acude a un capelán para confesar os seus pecados e recoñece que pecou moito, mais que o único que lle pesa e polo que está perdida é polo feito de ser vella,

\footnotetext{
Nom sei hoj' eu mais pecador burguesa de min; mais vede-lo que mi mais pesa: sôo velh'a, ai capelan! Sempre eu pequei, des que fui foduda, Pero direi-vos per que son perduda Sôo velha, ai capelan! (vv. 4-9)
}

Afons'Eanes do Coton dedica a Orraca López $(2,16)$ outra composición na que tamén observamos a preocupación da soldadeira pola posibilidade de que trobe nunha cantiga a unha vella, pois pensa que a poden identificar con ela, pregándolle:

- Por Deus, que vos fez, non trobedes a nulha velh'aqui, ca cuidaran que trobades a mim (vv. 4, 5, 6) 
Nestas dúas cantigas observamos claramente ata que punto a vellez podía ser un problema para as soldadeiras que eran moi conscientes de que un estado físico deteriorado significaría o fin vida profesional. Orraca López volve a ser nomeada por Afons'Eanes do Coton na cantiga Orraca López vi doente un dia $(2,16)$, na que o autor pregunta á soldadeira se está enferma, ao que ela responde que é vella, mais que pensa curar desa enfermidade. O trobador contesta que é unha tolemia sandar da vellez, pois trátase dunha doenza incurábel: "dixe-lh'eu: - Gram folia pensades,/se per velhece a guarecer cuidades" (v. 7-8). Nin sequera a famosa soldadeira Maria Balteira se libra de ser chamada vella por Johan Baveca que se mofa de súa idade na cantiga Par Deus, amigos, gran torto tomei $(64,21)$ ao relatar como insultou a unha vella, á que non identificou, e sorprendeuse sendo inxuriado por María Balteira, que se sentiu aludida polas súas palabras, como explica no refrán: "por ũa velha que eu deostei,/deostou-m'ora Maria Balteira"' (v. 5-6).

No verso 15 da cantiga de Alfonso X, Achei Sancha Anes encavalgada (18,1), que antes mencionamos como un claro contra-texto de retrato da cantiga de amor, tamén aparece unha referencia á vellez desa muller "dix'eu: - Ai, velha fududancua" (v. 15). Neste caso, a denominación vella vai reforzada polo epíteto obsceno "fudaduncua", que contribúe a salientar o significado pexorativo do termo. Este adxectivo con alta carga sexual é específico do escarnio galego portugués e estaría formado polo participio do verbo FUTUERE e por outros elementos identificados con FUTUTU IN CULU (CORRAL, 1996, p. 326). Utilízase como modificador, case sempre unido a velha e na dispositio do texto sitúase sempre na estrofa final, polo que se pode entender que debía ser utilizada polos trobadores como unha especie de culminación, que ademais ocupa o lugar da rima.

A pobreza asociada á vellez, como xa se comentou, é algo habitual. Algunhas cantigas nas que se observa claramente esta ligazón son Maria Negra 
desventuyrada $(125,20)$ de Pero García Burgalês ou Marinha Crespa, sabedes filhar $(120,21)$ de Pero da Ponte. Na primeira, a vellez aparece asociada á tolemia e á pobreza, mentres que na seguinte o tema da vellez é abordado de xeito indirecto a través da frase feita "a boi velho non lhi busques abrigo", que aparece repetido no refrán e que era un antigo dito popular do que podemos entender ben o significado. Nesta cantiga preséntasenos polo tanto, a unha soldadeira vella e que busca abrigo no inverno, polo que entendemos que non debía dispor de moitos recursos.

\subsection{As mencións ao órgano sexual}

Por último, dentro do apartado da descrición física, faremos unha breve mención á sexualidade, da que falaremos máis en profundidade no próximo apartado ao referirnos aos comportamentos sexuais das soldadeiras. Fixarémonos, para rematar coa parte física, nas mencións ao órgano sexual feminino.

Hai bastantes exemplos de composicións nas que se alude explicitamente ao sexo da soldadeira que a maior parte das veces aparece denominado conon. Este é o caso por exemplo da cantiga de Alfonso X, Fui eu poer a mâo noutro di$(18,20)$. No segundo verso desta cantiga vemos como o trobador se refire ao sexo feminino directamente e denomínao conon: "Fui eu poer a mão noutro dila a ũa soldadeira no conon" (v. 1-2). Afonso Eanes de Coton tamén menciona en varias ocasións o cono (vv. 2, 6, 7, 12) na cantiga Mari'Mateu, ir-me quer'eu daquen, (2,13), onde acusa á soldadeira de desexar sexualmente a outras mulleres. Na cantiga Marinha, en tanto folegares $(136,3)$ de Afonso Eanes do Coton é outra composición de contido altamente obsceno na que se mencionan tanto os órganos sexuais masculinos como femininos: 


\author{
tapo-t'ao primeiro sono \\ da mia pissa o teu cono, \\ e mi o nom veja nengum, \\ e dos colhês [esse] cû, \\ Como non rebentas Marinha? (vv. 11-15)
}

A última das cantigas sobre as soldadeiras nas que se menciona o sexo da muller de xeito explícito é Pedi eu o cono a ûa molher $(126,10)$ de Pero d'Ambroa.

Mais para alén das anteriormente mencionadas, hai outras cantigas nas que tamén se nomea a vaxina da muller recorrendo a palabras encubertas que en moitos casos nos permiten acceder ao dobre sentido obsceno da cantiga. É este o caso da cantiga Elvira López, aquí, noutro dia $(70,18)$, de Joan García de Guilhade, na que as palabras encubertas eran: "maeta" (v. 4), "casa" (vv. 10, 17) ou "porta" (v. 13). Pero da Ponte tamén utilizará a palabra chave "maeta" na composición Maria Pérez, a nossa cruzada $(120,20)$ na que relata como á volta da súa viaxe a Ultramar a soldadeira tería perdido todas bulas e as indulxencias que tería conseguido grazas á súa peregrinación debido a que os rapaces llas roubaban por non levar a maleta fechada. Na composición Maria Negra, desventuirada $(125,20)$ de Pero Garcia Burgalês tamén aparece o termo pousada (v. 11) para referirse á vaxina da soldadeira. Alfonso $X$ refírese á vaxina de xeito encuberto mediante o termo chaga na cantiga Dominga Eanes ouve sa baralha. Nela, como xa vimos, o autor describe un combate entre un mouro e a soldadeira cun claro dobre sentido sexual. É neste contexto no que a palabra chaga, referida a unha ferida de guerra que xa non curará máis segundo os médicos, adquire o sentido sexual: “E dizem meges que usam tal preite/que atal chaga jamais nunca cerra" (vv. 22-23).

Como vemos, as referencias ao corpo da muller son abundantes en relación ás que aparecen no xénero amoroso no que practicamente non existen e se restrinxen unicamente ás partes altas ou nobres do corpo, mentres que nas cantigas de escarnio aparecerán tamén mencionadas as partes baixas, incluíndo 
as partes sexuais. Así pois, as características máis destacadas no cancioneiro satírico das soldadeiras céntranse nos trazos inherentes á fealdade da época. Salientan, en particular, a cor negra da pel, por oposición á brancura e castidade da dama; o exceso de pelo corporal, a gordura, pero, sobre todo, a vellez.

\section{ADESCRICIÓN PSICOLÓXICA}

A descrición da psicoloxía das soldadeiras é moito máis ampla que a descrición física. A pesar disto, o retrato que se nos ofrece das calidades destas mulleres volve a ser, como na descrición física, feito por oposición ás características morais da dama ideal á que se canta nas cantigas de amor e que ten como principais características psicolóxicas a mesura e o bon sen. Ás soldadeiras atribúeselles na lírica medieval algunhas das conductas máis reprobábeis da sociedade da época, maioritariamente relacionadas cos seus comportamentos sexuais, o que non estraña tendo en conta que se trata de un discurso satírico no que se retrata a mulleres que pertencían a un grupo social marxinal que non se encaixaba nos moldes sociais da época. Neste apartado farase un estudo das principais características psicolóxicas ou morais polas que son criticadas, atendendo sobre todo aos aspectos da promiscuidade sexual, as relacións con membros doutras relixións, a falta de relixiosidade, a avaricia ou a mala educación.

\subsection{A promiscuidade}

A promiscuidade e o desmesurado apetito sexual é unha das características principais que se lle atribúen a estas mulleres, sendo precisamente este o tema máis recorrente nas 43 cantigas nas que son nomeadas. Na cantiga de Johan Soarez Coelho Luzia Sánchez, jazedes en gran falha $(79,33)$, preséntasenos a unha muller insatisfeita, porque o home non é 
capaz de manter relacións sexuais debido á impotencia. $\mathrm{O}$ autor atribúe o problema tanto á actividade excesiva que lle require a soldadeira como a unha posíbel enfermidade venérea ${ }^{4}$. É esta incapacidade sexual o motivo cómico principal e a soldadeira preséntase moi descontenta ante este feito: "Vejo-vos jazer migo muit'agravada,/Luzia Sánchez, porque nom fodo nada" (vv. 7-8). Resende de Oliveira (2001, p. 154) considera que se trata dun maldizer aposto, isto é, que está escrito en primeira persoa, pero posto na boca de outra persoa, mais isto é imposíbel de comprobar, posto que a cantiga non está acompañada de ningunha rúbrica explicativa que nos indique algo ao respeito. Hai que notar, ademais, que no refrán da cantiga o trobador se refire á soldadeira coa forma de tratamento Dona Luzia nun ton claramente irónico que contrasta co léxico obsceno utilizado no resto da cantiga.

Noutro texto de Pero Garcia Burgalés, María Negra, desventuyrada $(125,20)$ aparece descrita unha muller vella e pobre que xa non ten relacións con homes, mais que sigue mantendo un desmesurado apetito sexual que a leva a gastar os poucos cartos que ten en consoladores que acaba perdendo sempre no ano,
E já ela é probe tornada, comprando pissas, vedes que ventuira!
Pissa que compra pouco lhe dura, sol que a mete na sa pousada; ca lhi convém que ali moira entom de polmoeira ou de torcilhom, ou, per força, fica end'aaguada
Muit'é pera ventuira menguada, de tantas pissas no ano perder, (vv. 8-16).

Nesta composición aparecen ligadas varias das características que serán recorrentes na descrición das soldadeiras como a vellez, a pobreza ou a tolemia

\footnotetext{
4 "com foder e é com maloutia" (v. 22). Maloutia significaría molestia, enfermidade (venérea en xeral) segundo o glosario que atopamos en Graça Videira Lopes e Manuel Pedro Ferreira (2011).
} 
(v. 20, velha sandia). Ademais, chama a atención a utilización nesta cantiga de certo léxico relacionado con doenzas do gando cabalar como polmoeyra, torzilhon (v. 13) ou fica ende aguada (v. 14), que na época debían ser facilmente coñecidas por todo o mundo ${ }^{5}$. Esta alusión aos cabalos podería estar relacionada co gran tamaño das pissas que utiliza a soldadeira para satisfacer os seus desexos. Maria Perez é outra das soldadeiras ás que se lle atribúe unha grande actividade sexual, aínda que non dunha forma tan explícita como nas cantigas anteriores, como se pode ver no texto Maria Perez a nossa cruzada $(120,20)$ de Joan Soarez Coelho. Nel o trobador narra a súa volta de Terra Santa. A través de dobres sentidos explica como polo camiño foi perdendo todos os perdóns que de alí traía ao irse deitar cada noite. Trátase dun exemplo perfecto de equivocatio no que se accede ao sentido sexual a través dunha serie de palabras chave comúns no escarnio como maeta (v. 9) ou pousada (v. 18). Outro exemplo de promiscuidade atopámolo na cantiga que Afons'Eanes de Coton dedica a Mari Mateu $(2,13)$ na que se refire á homosexualidade da soldadeira como se pode apreciar no refrán: “Mari' Mateu, Mari' Mateu,/tam desejosa ch'és de cono com'eu“. A homosexualidade estaba completamente censurada pola sociedade cristiá da época mais a súa exposición era utilizada polos trobadores coa finalidade do cómico polo cómico.

\subsection{As relacións sexuais con mouros e xudeus}

As relacións sexuais con mouros e xudeus eran outro dos aspectos completamente censurados pola sociedade. Eran consideradas ilegais e o castigo era a pena de morte para o home e un apedramento para a muller cristiá como aviso, se era a primeira vez e a segunda vez, sería tamén morta. Isto é o

\footnotetext{
${ }^{5}$ Para o estudo deste tipo de léxico véxase C. Michaëlis de Vasconcelos, "Mestre Giraldo e os seus tratados de alveitaria e cetraria" (1910). Véxase tamén G. Pérez Barcala, Tratado de albeitaria (2004).
} 
disposto nas Partidas de Alfonso X, aínda que é difícil crer que isto se levase a cabo dun xeito moi ríxido nunha sociedade como a medieval na que o contacto entre as diferentes culturas era moi frecuente. Nas cantigas de escarnio atópanse tamén varias referencias a este tipo de relacións ilícitas entre soldadeiras e mouros ou xudeus. No texto de Alfonso X, Domingas Eanes ouve sa baralha $(18,11)$, que xa comentamos en apartados anteriores, o autor reproduce unha batalla entre a soldadeira e un cabaleiro mouro. Trátase dun equívoco erótico que utiliza a metáfora do combate militar no que a soldadeira tería vencido a pesar de acabar ferida pola lanza do cabaleiro. A ferida ou chaga que lle produce o cabaleiro, como vimos no punto anterior, encubre unha mención ao sexo da soldadeira que xa nunca máis será fechado. No último verso desta cantiga faise outra alusión a algún tipo de enfermidade venérea "e poren muit'á que é fistolada"(v. 28).

que atal chaga jamais nunca cerra,
se com quanta lã há em esta terra
a escaentassem, nem cõn'o azeite;
porque a chaga nom vai contra juso,
mais vai em redor, come perafuso,
e por en muit'há que é fistolada.(vv. 22-28)

Afons'Eanes de Coton, en Traj'agora Marinha Sabugal (2,23), utiliza de novo o mesmo símil guerreiro para referirse ás relacións da soldadeira cos mouros cando di "mais ora quer ir moiros guerreiar" (v. 5), nesta cantiga déixase claro a vontade da soldadeira de manter este tipo de relacións a pesar da oposición da súa vella criada que non quer ir canda ela,

mais ora quer ir moiros guerreiar, e quer consig[o] a velha levar mais a velha nom é doita da guerra (vv. 5-7)

Pero Garcia d'Ambroa refírese no texto O que Balteira ora quer vingar 
$(126,7)$ a vontade que ten María Balteira de vingarse das deshonras que sufriu por parte dos mouros, polo que se entende que terían mantido relacións. Di o trobador:

e os mouros pensse de os matar ca de todos gram desonrra colheu no corpo, ca non en outro logar (vv. 15-17)

Johan Baveca nun dos seus textos, Un escudeiro vi oj'arrufado $(64,28)$, dedicado a Maior García, menciona tamén as súas relacións tanto con mouros como con xudeus. O tema da cantiga é a reclamación que un escudeiro fai á soldadeira dunha débeda ao que ela responde que recorrerá a un xudeu e a un mouro,

aquel judeu com que hai baratado,

e um mouro, que há qui de chegar,

com que hei outrossi de baratar;

e, em como quer, farei-vos eu pagado (vv. 11-14)

Segundo a soldadeira, estes homes porán o diñeiro á súa disposición coa condición de facerlles unha carta de penhor (v. 20) como lle esixe o mouro que di:

-sol nom é pensado

que vós paguedes rem do meu haver,

meos d'eu carta sobre vós fazer,

ca um judeu havedes enganado, (vv. 18-21)

Por este fragmento pódese entender que o xudeu xa tería pagado sen conseguir ningunha garantía. Trátase novamente dun claro equívoco sexual no que se menciona a membros das dúas relixións coas que estaba sancionado manter relacións. 


\subsection{A falta de relixiosidade}

A relixiosidade das soldadeiras tamén é obxecto de burla en varias ocasións tanto ao referirse ás relacións sexuais que manteñen con membros do clero, que moitas veces van seguidas dun falso arrepentimento, para mostrar que non seguen como era debido as normas da doutrina cristiá. Isto non é estraño, posto que as sátiras que teñen como centro aos membros da xerarquía eclesiástica son moi abundantes no corpus das cantigas de escarnio, tendo en conta que eran parte fundamental da sociedade desa época. Pero Amigo de Sevilha alude a que Maior Garcia vive unicamente grazas ao que lle dan o arcediano e o dayam a cambio dos seus servizos na cantiga Mayor Garcia vi tan pobr'ogano $(116,13)$.

que, se nom fosse o arcediano, nom havia que deitar sobre si; ar cobrou pois sobr'ela o dayam; e por aquelo que lh'antr'ambos dam, (vv. 3-6)

Tamén ten como protagonista a Maior Garcia a composición de Johan Baveca Maior Garcia ssenpr'oyo dizer $(64,15)$, na que se repite a idea de que a soldadeira mantén relacións con eclesiásticos, mais neste caso dise que é porque quere garantir a salvación da súa alma polo que non se contenta con estar preto dun clérigo, senón que chega a estar con tres ("dous ou tres clerigos, hun a sazon", v. 13). Nesta cantiga utiliza o autor a aequivocatio centrada no comportamento sexual. Na cantiga de Alfonso X Fui poer a mâo noutro di- $(18,20)$, xa non se trata o tema das relacións entre soldadeiras e eclesiásticos, senón que se alude directamente á infracción das normas relixiosas. Neste texto o trobador fai referencia á obrigación que tiñan as prostitutas de absterse de practicar o seu oficio en determinados días do calendario litúrxico. Esta prohibición non era unicamente para as prostitutas, senón que se estendía a toda a sociedade 
cristiá $^{6}$, e como se pode imaxinar, unha desas datas sinaladas era a semana santa. É precisamente este momento, o día da Paixón de Cristo, ao que o rei Sabio alude nesta composición. A soldadeira increpa ao home por requirir os seus servizos nunha data tan inoportuna. O poeta manifestará repetidamente ao longo da cantiga o seu gran desexo sexual a través dunha serie da metáforas sacro-profanas e mesmo chega a culpar a Cristo do seu sufrimento que chega a comparar co do propio Deus. Debido a que o texto chegou ata nós incompleto, non fica moi claro se a soldadeira corresponde aos pedidos do poeta. Segundo Eukene Lacarra Lanz (2002, p. 78-84), o obxectivo de Alfonso X, ao crear este texto, foi o de criticar aos que mesturan o divino e o humano, mentres que para outros autores como M. Martins (1977), se trata unicamente dunha sátira relixiosa.

\subsection{A relación coa maxia e as supersticións}

Outro dos trazos que aparece nalgún caso caracterizando a estas mulleres é a súa relación coas artes máxicas e coas supersticións. Hai dous textos nos que se menciona a Maria Balteira que tratan este tema: na tenzón de Vasco Peres Pardal e Pedr'Amigo de Sevilha Pedr'Amigo, quero de vós saber $(154,8)$ atribúeselle á soldadeira o poder de excomungar e absolver, un poder que lle viría das súas relacións cos mouros. Nesta cantiga faise referencia ás conexións da soldadeira coas dúas culturas peninsulares.

ben de Meca ven

este poder, e, poy-lo outorgou

o patriarca des i mal levou (vv. 22-24)

Pero Garcia Burgalés en Maria Balteira, porque jogades $(125,19)$, acusa a

\footnotetext{
6 Tense coñecemento deste tipo de prohibicións polos libros penitenciais que se conservan principalmente a partir do s. IX, véxase E. Lacarra (2002, p. 81).
} 
María Balteira de blasfemar ("descreer"), mentres xoga aos dados o que podería deixala quedar en mala posición diante dos bons homens. É claro que esta cantiga tamén agocha un segundo sentido sexual cando se refire ao xogo. Ademais, tamén son descritas como arteiras e enganadoras, mulleres que non dubidan en enganar a calquera en favor do beneficio propio. Serían, polo tanto, egoístas e non compartirían os valores morais positivos dos que facían gala as damas dos xéneros amorosos. Pero Garcia Burgalês refírese a isto na cantiga Maria Negra vi eu, em outro dia $(125,21)$, na que o tema principal é a orixe do alcume da soldadeira que ela mesma lle rebela mentres vai andando. Nesta composición o autor refírese á muller como arteira, pois di "como vos sodes mulher arteyra" (v. 23) e que segundo M. Rodriguez Lapa, significaría 'experta' ou 'sagaz'.

Na composición de Vasco Perez Pardal, De qual engano prendemus, $(154,5)$, o trobador quéixase de que ao parecer María Balteira enganaba a todos os homes e incluso ao rei que, segundo o autor, "nom sab'el-rei parte" (v. 2). É curiosa a excepción que se fai con Pero d'Ambroa, que sería, segundo Perez Pardal, o "que a fode" (v. 22). Segundo algúns estudosos, estas alusións referiríanse a unha posible relación real, como dan a entender algunhas das cantigas deste xograr: O que Balteira ora quer vingar $(126,7)$ e Se eu no mundo fiz algum cantar $(126,15)$. O autor laméntase de lle ter prestado servizo amoroso e preséntaa como unha vella morrendo de amores por un clérigo co que gasta todo o que gañou. Na cantiga de Perez Pardal, na que se trata o engano da soldadeira aos demais homes, tamén se fai referencia á súa falta de mesura ("e nom há mesura sigo", v. 11) que é un dos riscos principais que caracterizan á dama nos xéneros amorosos. Vese neste texto, polo tanto, a clara oposición entre a senhor idealizada das cantigas de amor e a muller das cantigas de escarnio que representa todo o contrario. Pero Garcia d'Ambroa tamén se refire a Maria Perez $(126,9)$ como astuta á hora de sacarlles os cartos aos beesteiros (v. 1) e cualifícaa de "sabedor e arteira" (v. 7). Nesta composición como nalgunhas das 
anteriores tamén se utiliza o símil militar para chegar ao segundo sentido sexual, ao que neste caso se accede a través do verbo tirar.

Por último, no texto de Johan Baveca Estavam hoje duas soldadeiras $(64,11)$, xa comentado, no que se reproduce un diálogo entre dúas compañeiras de profesións, unha soldadeira dille á outra "Pero nós ambas somos muit'arteiras" (v. 17) o que indica que elas mesmas se consideraban audaces nos enganos. Esta cualificativo de arteiras ou enganadoras que tantas veces se lles atribúe a estas mulleres como é lóxico, non era positivo, mais en certo modo axuda a comprobar que eran consideradas mulleres intelixentes que recorrían a determinados enganos para sobrevivir.

Outra das características coas que se asocia ás soldadeiras é a avaricia. Na cantiga de Pedr' Amigo de Sevilha Moitos s'esfingen que an guaanhado $(116,19)$ trátase este tema a través da ridiculización do universo cortés. O poeta utiliza o tema das prendas de amor que intercambian os namorados para sinalar que a el Sancha Diaz nunca lle ten dado absolutamente nada sen que llo pagase, unicamente un peido (v. 7) e que nin sequera foi querendo. Varias cantigas que se refiren a Maria Balteira tamén tratan o tema do diñeiro que é preciso ter para estar coa soldadeira, como vemos na cantiga $O$ que veer quiser, ai, cabaleiro $(81,15)$, neste texto, como xa se apuntou ao inicio estaríase xogando coa duplicidade da actividade da soldadeira se di que quen queira ver a María Pérez ten que levar diñeiro: “O que veer quiser, ai, cavaleiro,/Maria Pérez, leve algun dinheiro" (vv. 1-2). Joan Vasquiz de Talaveira, en Bem viu dona Maria $(81,2)$, repite a mesma idea. Neste caso o trobador é rexeitado cando a soldadeira se decata de que non leva nada na esmoleira. Preséntasenos neste caso a soldadeira como unha interesada que unicamente se preocupa polos cartos.

Bem viu Dona Maria

Leve que nom tragia 
O comportamento das soldadeiras, a súa falta de educación ou de cortesía tamén serán criticados polos trobadores en numerosas ocasións. Un exemplo disto son as composicións nas que aparece o adxectivo "peideira", bastante común nas composicións dedicadas a estas mulleres e que equivalería a 'ordinaria' ou 'porca'. Este termo é utilizado, por exemplo, por J. Garcia de Guilhade en Dona Ouroana, pois já besta avedes $(70,16)$. Nesta cantiga, o autor proporciona consellos á soldadeira no seu novo estatuto de propietaria dun cabalo. O dobre sentido obsceno desenvólvese a partir dos dobres sentidos implícitos en besta (v. 1) e en cabalgar (v. 5). Para describir a esta muller utilízanse adxectivos como peideira ("sodes peideira", v. 14) ou puta fudaduncua (v. 17), que xa comentamos no apartado anterior. Na fiinda o trobador remata coa alusión á posíbel homosexualidade da soldadeira:

E, se ficardes en besta mũar, eu vos conselho sempr' a vos ficar ant' en mũacho novo ca en mũa (vv. 16-18)

Emprégase neste caso a oposición entre mûacho/mua (macho/femia) co valor de 'un'/'unha' amante, que debía ser usado e coñecido no léxico da época. Polo tanto, Guilhade aconsella á soldadeira que escolla a un rapaz en vez dunha rapaza (LAPA, 1965). Outra cantiga na que se documenta o adxectivo peideira é Maria negra, vi eu en outro día $(125,21)$. Pero Garcia Burgales comenta no último verso desta cantiga, "hei per i, [ca hei] preço de peideira" (v. 28). Este termo, grazas ao seu sentido cómico escatolóxico fai que sexa moi axeitado para este tipo de composicións. Ademais, alude á falta de educación e á ignorancia dos costumes refinados, propias de mulleres dunha clase social máis elevada. 


\section{CONSIDERACIÓNS FINAIS}

Ao longo deste traballo tentouse ofrecer unha visión panorámica da imaxe das soldadeiras que se ofrece na lírica medieval galego-portuguesa, atendendo exclusivamente ás referencias que atopamos nas 43 cantigas de escarnio e maldizer que, segundo os estudosos, se dedican a estas mulleres. Procuramos en cada un deses textos referencias ao aspecto físico das soldadeiras e tamén todas as referencias relativas ao xeito de ser, as súas costumes e comportamentos. Grazas a isto obtivemos unha descrición bastante estereotipada na que raramente aparecen referencias concretas ao aspecto físico e nas que os seus comportamentos e costumes son bastante esperábeis dentro da contra-moral da época. A laudatio á dama dos xéneros amorosos converterase, nas cantigas satíricas que mencionan ás soldadeiras, en vituperatio, sendo a fealdade ou a vellez as características corporais mais destacadas, mentres que dende unha perspectiva moral e comportamental os aspectos más destacados son a promiscuidade sexual, a falta de relixiosidade, a avaricia e o engano.

O feito de que as soldadeiras se movesen nos mesmos círculos sociais que os trobadores e os xograres como participantes do espectáculo trobadoresco converteunas no albo perfecto das mofas dos poetas, que encontraron nelas a posibilidade de inverter os trazos característicos da dama representada nos xéneros amorosos. Polo tanto, a descrición que se realiza das soldadeiras nas cantigas debe entenderse dentro dos parámetros literarios nos que se move o xénero do escarnio, intentando conseguir o riso do público a través da ridiculización do aspecto destas mulleres ou das mencións obscenas á súa sexualidade. 


\section{REFERENCIAS}

ARIAS FREIXEDO, Xosé B. Antoloxía de poesía obscena dos trovadores galego-portugueses. Santiago de Compostela: Positivas, 1995.

BLANCO, Carmen. María Balteira, muller leda sen lei: a loanza oculta no poema de Lorenzo Varela. Boletín da Real Academia Galega, Santiago de Compostela, n. 366, p. 1720, 2005.

BREA, Mercedes; LORENZO GRADÍN, Pilar (Dir.). Base de datos da Lírica Profana Galego-Portuguesa (MedDB), versión 2.3.3. Santiago de Compostela: Centro Ramón Piñeiro para a Investigación en Humanidades, 1998. Dispoñíbel en: [http://www.cirp.es/]. Acceso o: 28 de marzo de 2021.

CORRAL, Esther. As mulleres nas cantigas medievais. Sada: Castro, 1996.

CORRAL, Esther (Coord.). Guía para o estudo da lírica profana galego-portuguesa. Santiago de Compostela: Centro Ramón Piñeiro para a Investigación en Humanidades, 2010.

KLOBUCKA, Anna. Sobre a hipótese de uma herstory da literatura portuguesa. Veredas: Revista da Associação Internacional de Lusitanistas, Coimbra, n. 10, p. 13-25, 1 dez. 2008. Dispoñíbel en: [https://revistaveredas.org/index.php/ver/article/view/128/128]. Acceso o: 28 de marzo de 2021.

MENÉNDEZ PIDAL, Ramón. Poesía juglaresca y juglares. Orígenes de las literaturas románicas. 9. ed. Madrid: Espasa Calpe, 1990.

LACARRA LANZ, Eukene. Sobre la sexualidad de las soldadeiras en las cantigas d'escarnho e de mal dizer. Amor, escarnio y linaje en la literatura gallego-portuguesa. Bilbao: Universidad del País Vasco, 2002.

PÉREZ BARCALA, G. Tratado de albeitaria. Santiago de Compostela: Centro Ramón Piñeiro para a Investigación en Humanidades, 2004.

RESENDE DE OLIVEIRA, A. O trobador galego-portugués e o seu mundo. Lisboa: Notícias, 2001.

RODRIGUES LAPA, Manuel. Cantigas d'escarnho e mal dizer dos cancioneiros medievais galego.portugueses. Coimbra: J. Sá da Costa, 1965.

SAMYN, Henrique M. Sobre a "negrura" de Maria Negra: apontamentos sobre três cantigas satíricas de Pero Garcia Burgalês. Abriu, Barcelona, n. 9, p. 125-142, 2020.

VASCONCELOS, C. Michaëlis de. Mestre Giraldo e os seus tratados de Alveitaria e Cetraria. Revista Lusitana, Lisboa, v. XIII, 1910.

VIDEIRA LOPES, Graça. Cantigas de escárnio e mal dizer dos trobadores e jograis galegoportugueses. Lisboa: Estampa, 2002.

VIDEIRA LOPES, Graça; FERREIRA, Manuel Pedro (Coord.). Cantigas Medievais Galego Portuguesas [base de dados online]. Lisboa: Instituto de Estudos Medievais, FCSH/NOVA, 2011-. Dispoñíbel en: [http://cantigas.fcsh.unl.pt]. Acceso o: 28 de marzo de 2021. 
Nota do editor:

Artigo submetido para avaliação em: 29 de março de 2021.

Aprovado em sistema duplo cego em: 30 de maio de 2021. 